\title{
Hypertension, hypertrophy, heart failure
}

\author{
M Gary Nicholls
}

Heart failure presents a number of difficulties. Its very definition has proved taxing, and the clinical diagnosis is frequently incorrect. Patients with objective abnormalities of left ventricular function are not infrequently asymptomatic, hence treatment is often delayed. Even when a firm diagnosis is secured, only a minority of patients receive optimal medical treatment. Of concern is the increasing incidence and prevalence of heart failure in Western countries, with attendant high morbidity and mortality rates and escalating costs of management. The close association, as cause and effect, between hypertension and heart failure-well recognised in earlier years-appears to be dismissed or ignored by some observers, especially in the development of guidelines for the management of hypertension or heart failure.

Some of these matters will be discussed to emphasise the importance of long standing hypertension as a preventable risk factor for left ventricular hypertrophy and heart failure in Western countries.

Department of Christchurch School of Medicine, Christchurch Hospital, Christchurch, New Zealand M G Nicholls Correspondence to: Professor M G Nicholls.

\section{Heart failure: a public health problem}

Heart failure affects around one to three per cent of the population in Western countries, and the incidence and prevalence are increasing. ${ }^{2}$ In fact, the one to three per cent prevalence quoted is likely to be an underestimate when one considers the difficulties in making a clinical diagnosis of heart failure ${ }^{3-5}$ and the high incidence of asymptomatic cardiac dysfunction, ${ }^{6}$ especially after acute myocardial infarction.?

The economic cost of managing established heart failure is approximately one to two per cent of total health care expenditure. ${ }^{8-10}$ This enormous burden to patients and the taxpayer, accounted for largely by costs associated with hospital admission, is likely also to be an underestimate and to be increasing.

\footnotetext{
Glossary of trials

EWPHE-European Working Party on High Blood Pressure in the Elderly trial

SHEP-Systolic Hypertension in the Elderly Program

SOLVD-Studies of Left Ventricular Dysfunction

STOP-Hypertension-Swedish Trial of Old Patients with Hypertension

TOMHS-Treatment of Mild Hypertension Study
}

\section{Hypertension as a risk factor for heart failure}

Before the widespread availability of antihypertensive drugs, the commonest cause of heart failure in Western countries was hypertension. For example, $55 \%$ of patients who died from heart failure between 1910 and 1938 in a Minnesota study had, at necropsy, underlying hypertensive heart disease. ${ }^{11}$ The figure was $38 \%$ in the necropsy series of Wartman and Hellerstein carried out in Cleveland, Ohio, between 1935 and $1940 .^{12}$

There are few long term observational studies of sizeable hypertensive populations receiving no, or limited, treatment. What studies exist $\mathrm{t}^{13}$ indicate that congestive heart failure was the cause of death in more than $50 \%$ of hypertensive patients (table). Bechgaard determined that a lesser fraction $(24 \%)$ of total deaths in 1038 hypertensive (blood pressure $160 / 100 \mathrm{~mm} \mathrm{Hg}$ ), middle aged (53 years old) Danish patients, followed for 40 years from 1932, was due to heart failure, but this exceeded deaths from stroke $(17 \%)$ or myocardial infarction (16\%). ${ }^{14}$ In the study that Perera reported in $1955,50 \%$ of 500 essential hypertensive patients in New York followed until death in the absence of antihypertensive treatment developed heart failure. ${ }^{15}$ Here, as in the study of Bechgaard, ${ }^{14}$ heart failure was considered to have contributed to death in a much greater number of patients $(38 \%)$ than did stroke (9\%), myocardial infarction, and renal insufficiency (6\%).

The association between hypertension and heart failure was shown by Smirk in 1957 to be "dose-related", ${ }^{16}$ that is, the higher the arterial pressure, the greater was the risk of developing heart failure (fig 1). Workers in Framingham noted the same phenomenon 15 years later. ${ }^{17}$ Such a "dose" relation would be anticipated if the link between hypertension and heart failure was one of cause and effect.

The Framingham study, initiated in 1948, was pivotal in confirming an association between hypertension and the subsequent development of heart failure in Western society. Of 5192 subjects in the general population of Framingham followed for 16 years, 142 developed heart failure, of whom $75 \%$ had prior hypertension on routine biennial examinations. ${ }^{17}$ The original Framingham study was extended in 1971 to include children of the original participants and spouses of these children, in the Framingham Offspring Study. ${ }^{18}$ Among the total of 9405 participants followed from 1948 to 1988 , heart failure developed in 652 , of whom $70 \%$ of men and $78 \%$ of women 
Cause of death of patients with hypertensive disease as reported by various investigators *

\begin{tabular}{|c|c|c|c|c|c|c|c|c|c|c|c|c|c|c|}
\hline \multirow[b]{2}{*}{ Cause of death } & \multicolumn{2}{|c|}{$\begin{array}{l}\text { Murphy } \\
\text { et al }\end{array}$} & \multicolumn{2}{|c|}{ White } & \multicolumn{2}{|c|}{ Clawson } & \multicolumn{2}{|c|}{$\begin{array}{l}\text { Bell and } \\
\text { Clawson }\end{array}$} & \multicolumn{2}{|c|}{ Flaxman } & \multicolumn{2}{|c|}{$\begin{array}{l}\text { Goldring } \\
\text { and Chasis }\end{array}$} & \multicolumn{2}{|l|}{ Total } \\
\hline & $n$ & $\%$ & $n$ & $\%$ & $n$ & $\%$ & $n$ & $\omega_{0}$ & $n$ & $\%$ & $n$ & $\%$ & $n$ & ${ }^{\circ} \%$ \\
\hline $\begin{array}{l}\text { Congestive heart failure } \\
\text { Coronary thrombosis and }\end{array}$ & 171 & $56 \cdot 4$ & 53 & $53 \cdot 0$ & 78 & $56 \cdot 0$ & 187 & $44 \cdot 5$ & 122 & $64 \cdot 5$ & 56 & $49 \cdot 6$ & 667 & $52 \cdot 8$ \\
\hline sudden death & - & - & 31 & $31 \cdot 0$ & 37 & $26 \cdot 5$ & 67 & $15 \cdot 9$ & 15 & $7 \cdot 9$ & 22 & $19 \cdot 5$ & 172 & $13 \cdot 6$ \\
\hline Cerebral vascular accident & 45 & $14 \cdot 9$ & 6 & $6 \cdot 0$ & 16 & 11.5 & 81 & $19 \cdot 5$ & 13 & $6 \cdot 9$ & 17 & $15 \cdot 0$ & 178 & $14 \cdot 0$ \\
\hline Uraemia & 23 & $7 \cdot 6$ & 5 & $5 \cdot 0$ & 8 & $5 \cdot 5$ & 36 & $8 \cdot 5$ & 31 & $16 \cdot 4$ & 4 & 3.5 & 107 & $8 \cdot 5$ \\
\hline Other causes & 64 & $21 \cdot 1$ & 5 & $5 \cdot 0$ & $\cdots$ & --- & 49 & $11 \cdot 6$ & 8 & $4 \cdot 3$ & 14 & $12 \cdot 4$ & 140 & $11 \cdot 1$ \\
\hline Total & 303 & & 100 & & 139 & & 420 & & 189 & & 113 & & 1264 & \\
\hline
\end{tabular}

${ }^{\star}$ From Goldring W, Chasis H. Hypertension and hypotensive disease. NY Commonwealth Fund, 1945

Reproduced with permission from Doyle.

had an antecedent diagnosis of hypertension. Forty per cent of patients had both coronary heart disease and hypertension before developing heart failure (fig 2). Of importance is the observation that there was no change in the frequency of hypertension as the attributable cause of heart failure during the four decades of observation. ${ }^{11}$ Additional data from Framingham reveal that even borderline isolated systolic hypertension was associated with an increased risk of developing heart failure. ${ }^{21}$

The primacy of hypertension as the main risk factor for heart failure was confirmed in the Swedish study of men born in 1913, even

Figure 1 Relation of mean "basal" blood pressure (basal diastolic and basal systolic) $\div 2$ to the percentage incidence of congestive heart failure or left ventricular failure in a series of hypertensive patients. Reproduced with permission from Smirk."
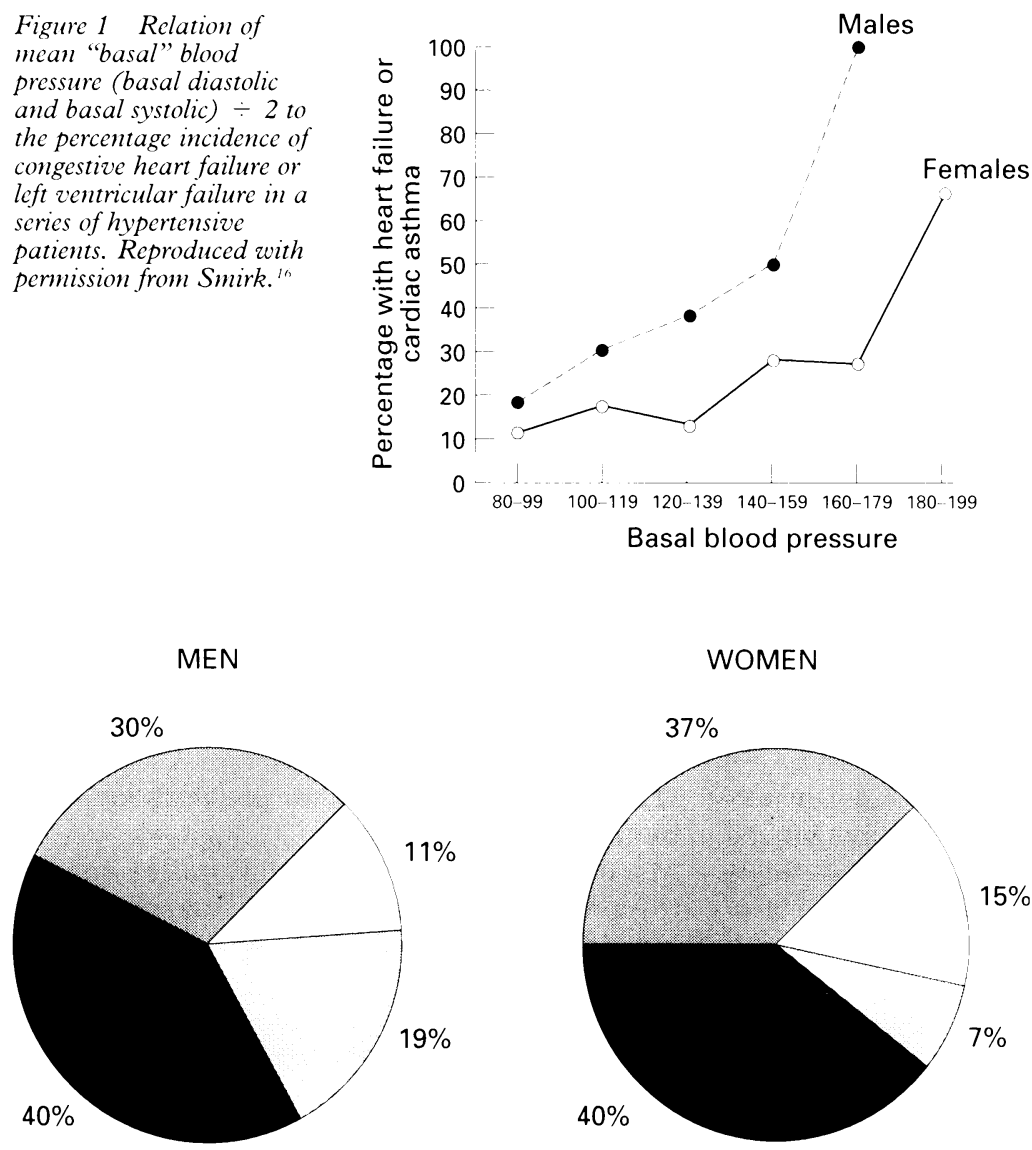

WOMEN

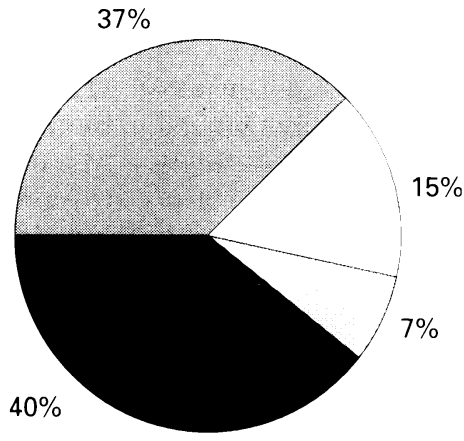

$\mathrm{n}=331$

$\mathrm{n}=321$

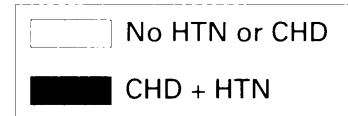

Hypertension alone

Coronary heart disease alone

Figure 2 Prevalence of coronary heart disease (CHD) and hypertension (HTN) alone, and in combination, among Framingham Heart Study patients with congestive heart failure. Reproduced with permission from Ho et al. ${ }^{1 \times}$ though hypertensives were defined narrowly as those receiving antihypertensive drug treatment or who had blood pressure readings of $175 / 115 \mathrm{~mm} \mathrm{Hg}$ or higher. ${ }^{2}$

More recently, hypertension was found in the USA to be the strongest predictor of hospital admission for congestive heart failure in both blacks and whites over a median period of 9.5 years (starting from 1978-1984) after an insurance examination. ${ }^{22}$ This study suggested that differences in the prevalence of hypertension, and diabetes and obesity to a lesser extent, accounted for the contrasting hospital admission rates for heart failure between blacks and whites. ${ }^{22}$ Even in the $1970 \mathrm{~s}$ and 1980s, therefore, hypertension appears to be the dominant risk factor for heart failure.

\section{Underestimation of hypertension as a risk factor for heart failure}

It is probable that the impact of hypertension as a cause of heart failure has been underestimated by available data. Why is this likely to be so?

First, patients with hypertension and impaired left ventricular function, whether systolic," diastolic, " or mixed, are not infrequently asymptomatic and would not have been defined as having heart failure, particularly in the early studies noted above.

Second, heart failure generally takes a considerable period of time to develop in hypertensives--except in the elderly. ${ }^{17}$ The numerous antihypertensive drug trials lasting two to five years in young and middle aged patients carried out over the last three decades $^{23}$ are too brief to reveal either the association of hypertension and heart failure in patients taking placebo, or the protective effects of antihypertensive drug treatment. Although the incidence of heart failure, compared to coronary heart disease and stroke, in placebo treated elderly hypertensives is difficult to define from published data, the protective effect of antihypertensive treatment in regard to heart failure is clear. ${ }^{21} 20$

Third, while exceptions can occur, arterial pressure generally falls with the development of heart failure. Previously hypertensive patients presenting to medical attention for the first time because of heart failure will often, therefore, be normotensive or hypotensive. Predisposing hypertension remains unsuspected in a percentage of these patients, especially since the earlier hypertrophied left 
ventricle can, through impaired coronary flow reserve with chronic myocardial ischaemia, transform into a dilated, failing ventricle. ${ }^{27}$

Fourth, blood pressure declines after acute myocardial infarction. ${ }^{28}$ Here again, prior hypertension can remain unsuspected since the first clinical presentation is acute myocardial infarction in a patient with now normal or low blood pressure. The true impact of hypertension as a predisposing factor for acute myocardial infarction and subsequent heart failure can only be appreciated from long term observational studies in unselected populations - as in the Framingham study. Hospital based studies will, predictably and inevitably, provide a different picture. ${ }^{29}$

Fifth, mortality after acute myocardial infarction in previously hypertensive men is almost three times that in men who had been normotensive. ${ }^{30}$ Those dying of heart failure soon after infarction are often hypotensive, and prior hypertension may again remain unsuspected.

Sixth, hypertensives have a disproportionately high rate of clinically unrecognised myocardial infarction. ${ }^{31}$ These patients are likely to seek medical attention when symptoms of cardiac failure develop-at which stage they may be normotensive, and the underlying disorder labelled as coronary heart disease. Yet again, only a long term Framingham-like study can reveal the likely contribution of longstanding hypertension to heart failure in this population of patients.

Finally, there is, experimentally, an association between left ventricular overload and arrhythmias, ${ }^{32}$ and, clinically, between hypertension, left ventricular hypertrophy, frequency of arrhythmias (including atrial fibrillation), and sudden death. ${ }^{33-35}$ The first clinical presentation in a patient's evolution from hypertension to heart failure may be with a symptomatic arrhythmia, at which time the arterial pressure can be near normal. Established heart failure may supervene, with no awareness that hypertension was the primary predisposing disorder and arrhythmia simply a precipitating factor.

At the risk of excessive repetition, the true relation between longstanding hypertension and the development of left ventricular hypertrophy ${ }^{36}$ and heart failure can only be gauged with accuracy from long term studies of unselected populations "undistorted by the selective bias of hospital admission practices". ${ }^{17}$ Recent and frequent claims that hypertension is now a lesser risk factor for heart failure than in earlier years seem unlikely and are not proven by the data presented.

\section{Does antihypertensive treatment prevent heart failure?}

In that epidemiological associations may not necessarily indicate cause and effect, it is pertinent in the present discussion to inquire whether antihypertensive treatment has an impact on the development of heart failure.

The Veteran's Administration Cooperative study reported in 1970 that antihypertensive drug treatment of males with diastolic pressures in hospital of $90-114 \mathrm{~mm} \mathrm{Hg}$ prevented the subsequent development of heart failure (no cases in treated patients, 11 cases in those randomised to placebo). ${ }^{37} 38$

A review of recent antihypertensive drug trials in the elderly shows a lesser frequency of clinical heart failure in patients receiving active antihypertensive therapy compared to those randomised to placebo. For example, there was a $63 \%$ reduction in severe congestive heart failure in the EWPHE ${ }^{24} ; 39$ patients developed heart failure in the placebo arm of STOP compared to 19 in the actively treated group $^{25}$; and in SHEP, 109 placebo treated patients developed left ventricular failure compared to 56 in the active group. ${ }^{26}$

Whereas this protective action of antihypertensive drug treatment is clear in the elderly and in severe grades of hypertension, it is less obvious from many recent studies. But cardiac failure, like mortality, ${ }^{39} 40$ is an end point of dubious usefulness for short term (two to five years) interventional studies in mild to moderate hypertension in the early and middle decades of life. Life expectancy - in large part through the development of heart failure-is shortened considerably in untreated young, mild essential hypertensives, ${ }^{41} 42$ but premature death may be decades away and, at least for heart failure, is unlikely to be detectable in brief interventional studies-except in the elderly.

If antihypertensive treatment is truly protective, how does one explain the paradox of increasing use of antihypertensive drug therapy -along with (in the USA) a decline in the population average for blood pressure ${ }^{43}$-yet an increasing prevalence of, hospital admissions for, and mortality from heart failure? ${ }^{3444}$ The answer is, most likely, that antihypertensive treatment postpones the development of clinical heart failure by some years or decades, but does not prevent it for ever. ${ }^{45}$ In addition, populations in Western countries are living longer and are therefore able to develop heart failure either directly from the myocardial effects of hypertension, or following myocardial infarction.

\section{Differing perspectives on preventing heart failure}

In view of the discussion so far, it is of interest to consider the recommendations of various individuals and the numerous "guidelines" published in recent years regarding treatment of hypertension and prevention of heart failure.

Framingham workers stated in 1972, "It is clear that a prophylactic approach (to preventing heart failure) is indicated and that the key to this is the early, vigorous and sustained control of hypertension". ${ }^{17}$ They went on to state, "To await the onset of symptoms or evidence of target-organ involvement before treating hypertension seems imprudent". ${ }^{17}$ They have reinforced this message repeatedly since, ${ }^{1846}$ and others concur. ${ }^{47}$

By contrast, recent guidelines for the management of hypertension, while acknowledging 
treatment benefits are probably being underestimated, focus firmly on coronary heart disease and stroke as the potentially preventable complications, ${ }^{48-50}$ basing this perspective largely on short term antihypertensive drug studies in middle aged patients. ${ }^{23}$ The extreme end of the spectrum is enunciated by the New Zealand guidelines, which suggest that antihypertensive drug treatment for hypertension (150-170 $\mathrm{mm} \mathrm{Hg}$ systolic and/or $90-100 \mathrm{~mm} \mathrm{Hg}$ diastolic) should, in general, be given only if the risk of a major cardiovascular disease event in five years is more than about $10 \% .^{51}$ The focus is on a five year time interval for stroke and myocardial infarction; heart failure receives no substantial mention. ${ }^{51}$ These recommendations would leave the vast majority of young and middle aged hypertensives without drug treatment for years, even decades.

Assessments of the cost-effectiveness of treating hypertension also tend to ignore long term implications and heart failure in particular, concentrating again on prevention of stroke and coronary heart disease from short term antihypertensive drug trials. ${ }^{52-54}$ The World Hypertension League, at least, is aware that "the full economic burden (of hypertension) is incompletely documented since the attributable risk of hypertension to diseases other than stroke and coronary heart disease is uncertain". ${ }^{55}$ Some commentators, while lamenting the high economic costs of treating established heart failure, fail to mention the possibility that the early diagnosis and treatment of hypertension might be cost-effective. ${ }^{56}$ The longer term view, discussed recently by Zanchetti, should be considered. ${ }^{40}$

Clearly, the perspective of individual commentators and committees is dependent upon whether they focus dominantly on brief antihypertensive drug trials of middle aged patients, or on data noted earlier in this paper, especially those from Framingham. Only the latter emphasise the link over the long term between hypertension and its complications, including heart failure. The link between hypertension and end stage renal failure, another disorder of interest to both clinicians and economists, likewise needs to be considered in the development of management guidelines for hypertension, if the long term view is felt to be important. ${ }^{57}$

\section{The future: selecting hypertensive patients for early treatment}

There is unlikely ever to be a placebo controlled trial of antihypertensive treatment in middle aged patients lasting decades that is capable of defining clearly the protective effect against heart failure (and other complications of hypertension); uncertainties will remain regarding which patients with mild or moderate essential hypertension, particularly in the early and middle decades of life, should receive drug treatment.

The presence of left ventricular hypertrophy in hypertension has powerful prognostic implications for the development of heart failure, as well as arrhythmias, sudden death, and myocardial ischaemia. ${ }^{58-60}$ Furthermore, regression of left ventricular hypertrophy by antihypertensive therapy is associated with a reduced risk of cardiovascular events, compared to a lack of regression. ${ }^{61} \mathrm{~A}$ case might be made, therefore, for estimation of left ventricular mass by echocardiography as a guide to drug treatment in all hypertensive individuals where advisability of treatment is otherwise uncertain. ${ }^{62}$ Such a policy has major implications since $12-20 \%$ of mild essential hypertensives and $50 \%$ of mild to moderate hypertensives have left ventricular hypertrophy. ${ }^{5863} \mathrm{~A}$ bonus of widespread use of echocardiography is the detection of abnormal left ventricular function, either systolic or diastolic, as a further guide to implementation of antihypertensive drug treatment.

Hypertensive patients with increased circulating concentrations of natriuretic peptides (or more likely their propeptides, which have slower plasma clearance rates and prolonged half lives in the circulation) may be entering an early stage of atrial distension or ventricular decompensation. ${ }^{64}$ Use of these markers has been proposed for the diagnosis of heart failure, ${ }^{65}$ and as a guide to angiotensin converting enzyme (ACE) inhibitor treatment after acute myocardial infarction. ${ }^{66}$ Their use, perhaps along with echocardiography, in deciding when to introduce antihypertensive treatment, might repay scrutiny.

Other circulating factors could provide some guide for antihypertensive treatment, although available data are preliminary. Procollagen peptides, for example, might reflect increased myocardial synthesis of type I and type III collagen in the hypertensive state. ${ }^{67}$ Attenuation of heightened collagen synthesis within the left ventricle by early antihypertensive treatment ${ }^{68}$ seems a laudable goal; however, more information is needed.

\section{Antihypertensive drugs, left ventricular hypertrophy, and heart failure}

If early and vigorous antihypertensive treatment seems desirable with a view to preventing long term complications, especially heart failure, is one group of antihypertensive agents preferable to others? No answer based on satisfactory study data exists.

In theory, antihypertensive drugs which block growth promoting and sodium retaining activities could provide more protection against heart failure than drugs with equal antihypertensive effects but which stimulate growth promoting and sodium retaining activities. There is widespread speculation that ACE inhibitors (and angiotensin II receptor blockers) might more successfully prevent and reverse the cardiac consequences, ${ }^{6970}$ and perhaps the vascular effects of hypertension ${ }^{71-73}$ rather than alternative drug groups-especially those which activate the renin-angiotensin and sympathetic nervous systems. Hope for such speculation comes from evidence, still short of being definitive, that some agents, especially ACE inhibitors, induce more rapid and possibly more complete reversal of left ventricular 
hypertrophy than other drug groups. ${ }^{74-76}$ Seemingly contradictory results from TOMHS $^{77}$ are understandable since it was a study ill equipped to address this particular issue. ${ }^{78}$

Additional support for the concept comes from SOLVD, in which a retrospective analysis suggested that ACE inhibition reduced morbidity and mortality, and also hospital admissions for heart failure, when compared to placebo in hypertensive patients with impaired left ventricular systolic function. ${ }^{79}$ Although a percentage of placebo patients received diuretic therapy, this was not a formal diuretic versus $A C E$ inhibitor trial, so there is no definite comparative information.

\section{Overview}

Heart failure in Western countries is a common, debilitating disorder with a high short term mortality. It accounts for one to two per cent of total health care budgets. The main risk factor identified in the first half of this century, and from subsequent long term population studies, is hypertension. Antihypertensive treatment delays, by years and perhaps decades, the onset of heart failure. Recent published recommendations and cost-benefit analyses for antihypertensive drug treatment largely ignore the potential benefits in the long term from delaying the onset or preventing heart failure (and other disorders such as chronic renal failure).

Consideration should be directed to the early identification of hypertensive patients with evidence of cardiac abnormalities, perhaps using a combination of echocardiography and plasma markers of myocardial dysfunction. Comparative effectiveness of the different antihypertensive drug groups in preventing and reversing the cardiovascular complications of hypertension needs to be clarified. In the case of heart failure and chronic renal failure, such comparative antihypertensive drug studies will need to be long term, or in elderly hypertensives, to give useful information.

1 Garg R, Packer M, Pitt B, Yusuf S. Heart failure in the 1990s: evolution of a major public health problem in cardiovascular medicine. $\mathcal{F}$ Am Coll Cardiol 1993;22:3-5A.

2 Eriksson $\mathrm{H}$. Heart failure: a growing public health problem f Intern Med 1995;237:135-41.

3 Marantz PR, Alderman MH, Tobin JN. Diagnostic heterogeneity in clinical trials for congestive heart failure. $A n n$ Intern Med 1988;109:55-61.

4 Vasan RS, Benjamin EJ, Levy D. Prevalence, clinical features and prognosis of diastolic heart failure: an epidemiologic perspective. $\mathcal{F}$ Am Coll Cardiol 1995;26:1565-74.

5 The Task Force on Heart Failure of the European Society of Cardiology. Guidelines for the diagnosis of heart failure. Eur Heart $₹$ 1995;16:741-51.

6 The SOLVD Investigators. Effect of enalapril on mortality and the development of heart failure in asymptomatic patients with reduced left ventricular ejection fractions patients with reduced left ventricular ejection fractions (published erratum appears in $N$ Engl $\mathcal{f}$

7 Gaudron P, Eilles C, Kugler I, Ertl G. Progressive left ventricular dysfunction and remodeling after myocardial infarction. Potential mechanisms and early predictors. infarction. Potential mech 1993;87:755-63.

8 McMurray J, Hart W, Rhodes G. An evaluation of the cost of heart failure to the National Health Service in the UK Brf Med Economics 1993;6:99-110.

9 Launois B, Reboul-Marty J, Battais J, Lefebvre P. Le coût de la sévérité de la maladie: le cas de l'insuffisance-cardiaque. $₹$ d'Economie Médicale 1990:8;395-412.

10 Doughty R, Yee T, Sharpe N, MacMahon S. Hospital admissions and deaths due to congestive heart failure in
New Zealand, 1988-91. N Z Med f 1995;108:473-5.

11 Clawson BJ. Incidence of types of heart disease among 30,265 autopsies, with special reference to age and sex. Am Heart $\mathcal{F}$ 1941;22:607-24

12 Wartman WB, Hellerstein HK. The incidence of heart disease in 2,000 consecutive autopsies. Annals Int Med 1943;28:41-65.

13 Doyle AE. Does hypertension predispose to coronary disease? Conflicting epidemiological and experimental evidence. Am 7 Hypertens 1988;1:319-24.

14 Bechgaard P. A 40 years' follow-up study of 1000 untreated hypertensive patients. Clin Sci Mol Med Suppl 1976;3:673-5S.

15 Perera GA. Hypertensive vascular disease: description and natural history. F Chron Dis 1955;1:33-42.

16 Smirk FH. Congestive heart failure. In: Smirk FH, ed. High arterial pressure. Oxford: Blackwell, 1957:86-8.

17 Kannel WB, Castelli WP, McNamara PM, McKee PA, Feinleib M. Role of blood pressure in the development of congestive heart failure. The Framingham study. $N$ Engl f Med 1972;287:781-7.

18 Ho KK, Pinsky JL, Kannel WB, Levy D. The epidemiology of heart failure: the Framingham Study. $\mathcal{f} \mathrm{Am}$ Coll Cardiol 1993;22:6-13A.

19 Ho KK, Anderson KM, Kannel WB, Grossman W, Levy $D$. Survival after the onset of congestive heart failure in Framingham Heart Study subjects. Circulation 1993;88: 107-15.

20 Sagie A, Larson MG, Levy D. The natural history of borderline isolated systolic hypertension. $N$ Engl $f$ Med 1993;329:1912-7.

21 Eriksson H, Svärdsudd K, Caidahl K, Bjurö T, Larsson B, Welin L, et al. Early heart failure in the population. The study of men born in 1913. Acta Med Scand 1988;223: 197-209.

22 Alexander $M$, Grumbach $K$, Selby J, Brown AF, Washington E. Hospitalization for congestive heart failure. Explaining racial differences. $\mathcal{F} A M A$ 1995;274: 1037-42.

23 Collins R, Peto R, MacMahon S, Hebert P, Fiebach NH, Eberlein KA, et al. Blood pressure, stroke, and coronary heart disease. Part 2. Short-term reductions in blood pressure: overview of randomised drug trials in their epipressure: overview of randomised drug trials in

24 Amery A, Birkenhäger W, Brixko P, Bulpitt C, Clement D, Deruyttere $M$, et al. Mortality and morbidity results from Deruyttere $\mathrm{M}$, et al. Mortality and morbidity results from the European Working Party on High B

25 Dahlö B, Lindholm LH, Hansson L, Schersten B, Ekbom T, Wester PO. Morbidity and mortality in the Swedish Trial in Old Patients with Hypertension (STOPHypertension). Lancet 1991;338:1281-5.

26 SHEP Cooperative Research Group. Prevention of stroke by antihypertensive drug treatment in older persons with isolated systolic hypertension. Final results of the Systolic Hypertension in the Elderly Program (SHEP). $¥ A M A$ 1991;265:3255-64.

27 Vogt M, Strauer BE. Systolic ventricular dysfunction and heart failure due to coronary microangiopathy in hypertensive heart disease. Am 7 Cardiol 1995;76:48-53D.

28 Kannel WB, Sorlie P, Castelli WP, McGee D. Blood pressure and survival after myocardial infarction: the Framingham study. Am $\mathcal{F}$ Cardiol 1980;45:326-30.

29 Andersson B, Waagstein F. Spectrum and outcome of congestive heart falure in a hospitalized population. $A m$ Heart $\mathcal{F}$ 1993;126:632-40.

30 Rabkin SW, Mathewson FA, Tate RB. Prognosis after acute myocardial infarction: relation to blood pressure values before infarction in a prospective cardiovascular values before infarction in a prospe
study. $A m \mathcal{F}$ Cardiol 1977;40:604-10.

31 study. Am $\mathcal{F}$ Cardiol $1977,40.604-10$. myocardial infarction and hypertension: the Framingham myocardial infarction and hypertension

32 Sideris DA Toumanidis ST, Kostis EB, Diakos A Moulopoulos SD. Arrhythmogenic effect of high blood pressure: some observations on its mechanism. Cardiovasc Res 1989;23:983-92.

33 Kannel WB, Abbott RD, Savage DD, McNamara PM. Epidemiologic features of chronic atrial fibrillation: the Framingham study. $N$ Engl f Med 1982;306:1018-22.

34 Anderson KP. Sudden death, hypertension, and hypertrophy. $f$ Cardiovasc Pharmacol 1984;6(suppl 3):S498-503.

35 Ghali JK, Kadakia S, Cooper RS, Liao YL. Impact of left ventricular hypertrophy on ventricular arrhythmias in the absence of coronary artery disease. $\mathcal{F} \mathrm{Am}$ Coll Cardiol 1991;17:1277-82.

36 Lauer MS, Anderson KM, Levy D. Influence of contemporary versus 30-year blood pressure levels on left ventricular mass and geometry: the Framingham Heart Study. $\mathcal{F}$ Am Coll Cardiol 1991;18:1287-94.

37 Effects of treatment on morbidity in hypertension. II. Results in patients with diastolic blood pressure averaging 90 through $114 \mathrm{~mm} \mathrm{Hg}$. $¥ A M A$ 1970;213:1143-52.

38 Effects of treatment on morbidity in hypertension. III. Influence of age, diastolic pressure, and prior cardiovascular disease; further analysis of side effects. Circulation 1972;45:991-1004.

39 Hansson L. Does drug treatment improve survival in mildto-moderate hypertension? $f$ Hypertens $1995 ; 13: 1354-5$.

40 Zanchetti A. Antihypertensive therapy: pride and prejudice. $\mathcal{f}$ Hypertens 1995;13:1522-8.

41 Lew EA. High blood pressure, other risk factors and longevity: the insurance viewpoint. $\mathrm{Am} \mathcal{f} \mathrm{Med} 1973 ; 55$; 281-94. 
42 Metropolitan Life Insurance Company. Blood pressure: insurance experience and its implications. New York: Metropolitan Life Insurance Company, 1961.

43 Drizd T, Dannenberg AL, Engel A. Blood pressure level in persons 18-74 years of age in 1976-1980, and trends in BP from 1960-1980 in the United States. In: Dept. Of Health and Human Services Vital and health statistics. Series 11, No 234. Washington, DC: Public Health Service, National Center for Health Statistics; 1986 July. Publication No: PHS-86-1684:1-68.

44 Ghali JK, Cooper R, Ford E. Trends in hospitalization rates for heart failure in the United States, 1973-1986. Evidence for increasing population prevalence. Arch Intern Med 1990;150:769-73.

45 Yusuf S, Thom T, Abbott RD. Changes in hypertension treatment and in congestive heart failure mortality in the United States. Hypertension 1989;13:174-9.

46 Kannel WB. Framingham study insights into hypertensive risk of cardiovascular disease. Hypertens Res risk of cardio

47 Lenfant C. Report of the Task Force on Research in Heart Failure [news]. Circulation 1994;90:1118-23.

48 Sever P, Beevers G, Bulpitt C, Lever A, Ramsay L, Reid J, et al. Management guidelines in essential hypertension report of the second working party of the British Hypertension Society. BMF 1993;306:983-7.

49 Guidelines Subcommittee of the WHO/ISH Mild Hypertension Liaison Committee. 1993 guidelines for the management of mild hypertension. Memorandum from a World Health Organization/International Societ of Hypertension meeting. Hypertension 1993;22:392-403.

50 The fifth report of the Joint National Committee on Detection, Evaluation, and Treatment of High Blood Pressure (JNC V). Arch Intern Med 1993;153:154-83.

51 Guidelines for the Management of Mildly Raised Bloo Pressure in New Zealand. Core Services Committee, PO Box 5013, Wellington, New Zealand.

52 Johannesson $M$. The cost effectiveness of hypertension treatment in Sweden. Pharmaco Economics 1995;7: 242-50.

53 Johannesson $M$. The cost-effectiveness of the switch towards more expensive antihypertensive drugs. Health Policy 1994;28:1-13.

54 Swales ID. The Harveian Oration of 1995. The growth of medical science: the lessons of Malthus. $\mathscr{f} R$ Coll Physicians Lond 1995;29:490-501.

55 World Hypertension League. Economics of hypertension control. Bull WHO1995;73:417-24.

56 O'Connell JB, Bristow MR. Economic impact of heart failure in the United States: time for a different approach. ure in the United States: time for a differen

57 Klag MJ, Whelton PK, Randall BL, Neaton JD, Brancati FL, Ford CE, et al. Blood pressure and end-stage renal FL, Ford CE, et al. Blood pressure and end-
disease in men. $N$ Engl $₹$ Med 1996;334:13-8.

58 Frohlich ED, Apstein C, Chobanian AV, Devereux RB Dustan HP, Dzau V, et al. The heart in hypertensio (published erratum appears in $N$ Engl f Med 1992;327: 1768). N Engl f Med 1992;327:998-1008.

59 Bikkina M, Larson MG, Levy D. Asymptomatic ventricula arrhythmias and mortality risk in subjects with left venricular hypertrophy. $7 \mathrm{Am}$ Coll Cardiol 1993:22:1111-6.

60 Levy D, Garrison RJ, Savage DD, Kannel WB, Castelli WP. Prognostic implications of echocardiographically determined left ventricular mass in the Framingham Heart Study. N Engl F Med 1990;322:1561-6.

61 Muiesan ML, Salvetti $M$, Rizzoni $D$, Castellano $M$ Donato F, Agabiti-Rosei E. Association of change in left ventricular mass with prognosis during long-term antihypertensive treatment. $\mathcal{F}$ Hypertens 1995;13:1091-5.

62 Mensah GA, Pappas TW, Koren MJ, Ulin RJ, Laragh JH,
Devereux RB. Comparison of classification of the severity of hypertension by blood pressure level and by World Health Organization criteria in the prediction of concurrent cardiac abnormalities and subsequent complication in essential hypertension. F Hypertens 1993;11:1429-40.

63 Devereux RB, Roman MJ. Hypertensive cardiac hypertrophy: pathophysiologic and clinical characteristics. In Laragh $\mathrm{JH}$ and Brenner BM, eds. Hypertension, pathophysiology, diagnosis, and management. New York: Raven Press, 1995:409-32.

64 Nakagawa O, Ogawa Y, Itoh H, Suga S, Komatsu Y Kishimoto I, et al. Rapid transcriptional activation and early mRNA turnover of brain natriuretic peptide in cardiocyte hypertrophy. Evidence for brain natriuretic peptide as an "emergency" cardiac hormone against venpeptide as an "emergency" cardiac hormone ag

65 Struthers AD. Prospects for using a blood sample in the diagnosis of heart failure. $Q \mathcal{F} M e d$ 1995;88:303-6.

66 Motwani JG, McAlpine H, Kennedy N, Struthers AD. Plasma brain natriuretic peptide as an indicator for angiotensin-converting-enzyme inhibition after myocarangiotensin-converting-enzyme inhibition

67 Díez J, Laviades C, Monreal I, Gil MJ, Panizo A, Pardo J. Toward the biochemical assessment of myocardial fibrosis in hypertensive patients. Am $\mathcal{F}$ Cardiol 1995;76:14-17D.

68 Weber KT, Brilla CG, Cleland JG, Cohn JN, Hansson L Heagerty AM, et al. Cardioreparation and the concept of modulating cardiovascular structure and function. Blood Pressure 1993;2:6-21

69 Raman VK, Lee YA, Lindpaintner K. The cardiac reninangiotensin-aldosterone system and hypertensive cardiac hypertrophy. Am ₹ Cardiol 1995;76:18-23D.

70 Westerhof N, O'Rourke MF. Haemodynamic basis for the development of left ventricular failure in systolic hypertension and for its logical therapy. $f$ Hypertens 1995 13:943-52.

71 Schachter $M$. Drug-induced modification of vascular strucure: effects of antihypertensive drugs. Am Heart $\mathcal{f} 1991$ 122:316-23.

72 Thybo NK, Stephens N, Cooper A, Aalkjaer C, Heagerty AM, Mulvany MJ. Effect of antihypertensive treatment on small arteries of patients with previously untreated essential hypertension. Hypertension 1995;25:474-81.

73 Van Bortel LM, Kool MJ, Spek JJ. Disparate effects of antihypertensive drugs on large artery distensibility and compliance in hypertension. Am f Cardiol 1995;76:46-9E.

74 Dahlöf B, Pennert K, Hansson L. Reversal of left ventricular hypertrophy in hypertensive patients. A meta-analysis of 109 treatment studies. Am f Hypertens 1992;5:95-110.

75 Richards AM, Nicholls MG, Crozier IG Role of ACE inhibitors in hypertension with left ventricular hypertrophy. Br Heart f 1994;72:S24-32.

76 Agabiti-Rosei E, Ambrosioni E, Palù CD, Muiesan ML Zanchetti A. ACE inhibitor ramipril is more effective than the $\beta$-blocker atenolol in reducing left ventricular mass in hypertension. Results of the RACE (ramipril cardioprotective evaluation) study. $\mathcal{F}$ Hypertens $1995 ; 13$

77 Liebson PR, Grandits GA, Dianzumba S, Prineas RJ, Grimm RH, Neaton JD, et al. Comparison of five antihypertensive monotherapies and placebo for change in left ventricular mass in patients receiving nutritional-hygienic therapy in the Treatment of Mild Hypertension Study (TOMHS). Circulation 1995;91:698-706.

78 Devereux RB, Dahlöf B. Criteria for an informative trial of left ventricular hypertrophy regression. $f$ Human Hypertens 1994;8:735-9.

79 Kostis JB. The effect of enalapril on mortal and morbid events in patients with hypertension and left ventricular dysfunction. Am $\mathcal{F}$ Hypertens 1995;8:909-14. 